\title{
A FORMAÇÃO E ATUAÇÃO DOCENTE NA DISCIPLINA DE CIÊNCIAS EM ESCOLAS DO CAMPO NA AMAZÔNIA PARAENSE
}

\section{THE FORMATION AND TEACHING PERFORMANCE IN THE SCIENCE DISCIPLINE IN RURAL SCHOOLS IN AMAZONIA PARAENSE}

\author{
Walcinéia Duarte Tenório (cyber.mmx2015@hotmail.com) \\ Secretaria de Educação, Prefeitura de Porto de Moz (PA) \\ Universidade Federal do Pará, Campus de Altamira, Faculdade de Etnodiversidade \\ Marcos Marques Formigosa. (mformigosa@ufpa.br) \\ Universidade Federal do Pará, Campus Altamira, Faculdade de Etnodiversidade \\ Universidade do Vale do Taquari (UNIVATES/PPGEnsino) \\ Carla Giovana Souza Rocha (crocha@ufpa.br) \\ Universidade Federal do Pará, Campus Altamira, Faculdade de Etnodiversidade \\ Ronaldo Henrique Santana (ronaldobio2@gmail.com) \\ Universidade Federal do Pará, Campus Altamira, Faculdade de Etnodiversidade
}

\begin{abstract}
Resumo: Uma boa formação docente implica no processo de ensino e aprendizagem que qualifique e direcione o profissional para atuar em sua área de formação, mas não é raro encontrarmos professores em exercícios sem a formação na área, sobretudo nas escolas do Campo. Esse trabalho tem como objetivo geral analisar os reflexos da ausência de formação específica na atuação de docentes na disciplina de Ciências em escolas do campo, no município de Porto de Moz, Pará. Os interlocutores da pesquisa foram três professores que atuam nos anos finais do ensino fundamental com a disciplina de Ciências em escolas do campo. Além da observação e diário de campo, realizamos entrevistas, a partir de um roteiro com perguntas semiestruturadas, que, a posteriori, foram gravadas e transcritas. Esses dados foram analisados numa perspectiva qualitativa, onde identificamos que a predominância de professores sem formação na área de Ciências, falta de formação pedagógica e de apoio oferecido pela Secretaria Municipal de Educação, além de um quadro que revela a precarização do trabalho dos educadores que atuam no campo.
\end{abstract}

Palavras-chave: Qualificação docente; Ciências da Natureza; Educação do Campo; Classes multisseriadas.

Abstract: Good teacher education implies the teaching and learning process that qualifies and directs the professional to work in their area of training, but it is not uncommon to find teachers in exercises without training in the area, especially in rural schools. This work has as its general objective to analyze the reflexes of the lack of specific formation in the performance of teachers in the discipline of Sciences in rural schools, of Porto de Moz, Pará. The interlocutors of the research were three teachers who work in the final 
years of elementary school with the discipline of science in rural schools. In addition to observation and field diary, interviews were conducted from a script with semi-structured questions, which were later recorded and transcribed. These data were analyzed from a qualitative perspective, where it was identified that the predominance of teachers without training in Sciences, lack of pedagogical training and support offered by the Municipal Education Department of the, in addition to a framework that reveals the precariousness of work of educators working in the field.

Keywords: Teaching qualification; Natural sciences; Rural education; Multigrade classes.

\section{INTRODUÇÃO}

No atual cenário educacional do Brasil, reflexões sobre o processo educativo escolar oferecido aos povos do campo estão evidenciadas, por exemplo, nos estudos que trazem a problemática do fechamento de escolas e precarização das condições do mesmo para essas populações (HAGE, 2011; 2014) está em evidência, o que tem instigado o desenvolvimento de pesquisas em torno da Educação do Campo, e tem contribuído para retratar o contexto educacional em suas especificidades locais e regionais. As reflexões sobre a temática foram reforçadas a partir de pesquisas e estágios realizados no curso de Licenciatura em Educação do Campo ${ }^{1}$ que tem permitido imersões diretas com o chão da escola pública, por meio da Pedagogia da Alternância, que se desenvolve entre dois tempos ${ }^{2}$ formativos e se constituem como indissociáveis e complementares.

Nesses TC's foi possível vivenciar a realidade educacional da educação do campo e conhecer os problemas, as dificuldades e os desafios enfrentados pela comunidade escolar. Todos os TC's geraram muitas informações e descobertas que tinham como objetivo conhecer a estrutura e funcionamento da escola do campo, perpassando pelas

\footnotetext{
${ }^{1}$ Curso oriundo do PRONACAMPO que prevê, dentre as ações, a ampliação e qualificação e oferta da Educação Superior às populações do campo, por meio da formação inicial e continuada de professores para atuarem nos anos finais do ensino fundamental e no ensino médio, em uma das áreas do conhecimento: Linguagens e Códigos, Ciências Humanas e Sociais, Ciências da Natureza, Matemática e Ciências Agrárias (BRASIL, 2013).

${ }^{2}$ No curso de Educação do Campo, da Universidade Federal do Pará, Campus Universitário de Altamira, Faculdade de Etnodiversidade, a Pedagogia da Alternância ocorre da seguinte forma: o Tempo Universidade (TU), com aulas das disciplinas da matriz curricular de forma intensiva, nos meses de janeiro, fevereiro, julho e agosto; e, o Tempo Comunidade (TC), que ocorre no intervalo entre os TU's. O TC é o período no qual o acadêmico retorna para seu local de pertença e desenvolve suas pesquisas, orientada por um docente do curso e apoiadas em diferentes autores, a partir das orientações e diálogos no decorrer do TU. São oito TU's e oito TC's, cada um por semestre letivo, distribuídos ao longo dos 4 (quatro) anos do curso (UFPA, 2015).
} 
práticas docentes e currículo desenvolvidos na escola pertencente à comunidade de uma das autoras, aluna do curso e residente no município de Porto de $\mathrm{Moz}^{3}$, no Pará.

O que mais chamou atenção foram os dados obtidos no decorrer do TC III, realizado no segundo semestre de 2016, em que se investigou acerca da situação do processo de ensino e aprendizagem na disciplina de Ciências ${ }^{4}$. A partir do contato com os professores dessa disciplina, e considerando a imersão por meio dos outros TC's, constatamos diferentes problemáticas nas escolas do campo do município, que vêm se estendendo há anos, e que têm implicado no processo de ensino e aprendizagem na disciplina de Ciências e outras.

Dentre os problemas evidenciados, percebemos que a carga horária é muito baixa, uma vez que a disciplina é trabalhada apenas uma vez na semana, com três aulas de 35 (trinta e cinco) minutos nos $7^{\circ}$ e $9^{\circ}$ anos, e duas aulas de 35 (trinta e cinco) minutos nos $6^{\circ}$ e $8^{\circ}$ anos, quando o recomendado são três aulas de 45 (quarenta e cinco) minutos para cada turma/ano. Mas, o que despertou bastante interesse foi a atuação dos professores sem formação específica na área de Ciências.

Essa questão ficou mais evidenciada no decorrer dos Estágios Supervisionados ${ }^{5}$ I e II, ocorridos em 2017 e 2018, respectivamente. Tanto no período da observação, quanto da regência, percebeu-se a insegurança do professor regente em determinados conteúdos, como o uso de termos técnicos, àqueles que envolvessem cálculos matemáticos presentes nos assuntos de Química e Física no $9^{\circ}$ ano do ensino fundamental. Além disso, eram perceptíveis algumas deficiências presentes nas metodologias e na relação didático/pedagógica com os alunos.

Diante disso, considerada a importância da disciplina de Ciências nas escolas do campo e os problemas enfrentados pelos profissionais atuantes, traçou-se o seguinte problema: qual a relação entre a qualificação e a atuação docente na disciplina de Ciências nas escolas do campo localizadas no município de Porto de Moz, Pará? Para responder a

\footnotetext{
${ }^{3}$ Município paraense, localizado às margens do Rio Xingu. Possui 33.953 habitantes, desses, 57\% residem na área rural (IBGE, 2010).

${ }^{4}$ No município de Porto de Moz, a disciplina de Ciências recebe o nome de Ciências Físicas e Biológicas (CFB), neste manuscrito, faremos uso do termo Ciências ou CFB.

${ }^{5} \mathrm{O}$ curso possui quatro Estágios Supervisionados, distribuídos no Ensino Fundamental (Estágios I e II) e no Ensino Médio (Estágios III e IV). Cada um deles possui carga horária de 100h, distribuídas entre: 60h orientação/formação no decorrer do TU; 10h de observação e 30h de regência.
} 
tal questionamento, elaboramos como objetivo geral: analisar os reflexos da formação profissional na atuação docente na disciplina de Ciências em escolas do campo, no município de Porto de Moz, Pará. E como objetivos específicos: a) verificar a formação profissional dos docentes que atuam na disciplina de Ciências da Natureza nas escolas do campo do município; b) conhecer os motivos que levaram os docentes a ministrarem a disciplina de Ciências da Natureza sem a formação específica na área.

Partimos do princípio de que a não formação na área pode implicar diretamente no processo de ensino e aprendizagem e, consequentemente, a aquisição de competências e desenvolvimento de habilidades por parte dos alunos. Além disso, o professor que atua na escola do campo necessita de uma formação que dê conta de uma realidade educacional específica e diferenciada, como rege a legislação vigente.

\section{CAMINHOS METODOLÓGICOS}

Primeiramente, como fase exploratória da pesquisa, procedemos ao levantamento de informações junto à SEMED de Porto de Moz, Pará. Essas informações foram adquiridas por meio de um ofício emitido à SEMED, que teve o intuito de saber a quantidade de professores de Ciências que atuam nas escolas do campo no município, bem como a formação de cada um deles.

Feito isso, elegemos os interlocutores da pesquisa: três professores que atuam em três diferentes escolas do campo, que serão identificados pelas letras maiúsculas A, B e $\mathrm{C}$, com a finalidade de manter o sigilo de suas identidades. Realizamos entrevistas em abril de 2019, mediante um roteiro semiestruturado, com perguntas abertas, permitindo, assim, aos interlocutores responderem às perguntas a partir de um diálogo, conforme iam sendo instigados, o que trouxe muitos elementos das suas experiências referentes ao tema discutido.

As entrevistas foram gravadas em áudio e, posteriormente, transcritas na íntegra, sem nenhum tipo de ajuste, como forma de respeito aos traços orais dos interlocutores. Além das entrevistas, fizemos os registros em diário de campo, a partir de observações tanto no decorrer das entrevistas, quanto no andamento dos TC's e Estágios Supervisionados. Os dados gerados foram investigados segundo o referencial teórico que 
sustenta a análise, numa perspectiva qualitativa que, segundo Chizzotti (2006), faz um diagnóstico crítico e reflexivo do fenômeno, na busca de interpretar os significados que a ele estão sendo atribuídos, ocorridos num dado contexto histórico, o que facilita uma compreensão detalhada do objeto estudado.

Também foram considerados os dados gerados no período de observação e regência dos Estágios supervisionados do curso de Licenciatura em Educação do Campo, que constavam nos relatórios da discente do curso.

\section{BREVE HISTÓRICO DO ENSINO DE CIÊNCIAS NO BRASIL}

O ensino de Ciências, na década de 1960, ocorreu no Brasil apenas nas duas últimas séries do ginásio, com caráter meramente teórico; no entanto, não era obrigatório. Em 1961, é promulgada a Lei ${ }^{\circ}$ 4024/61 (BRASIL, 1961), que norteava as discussões sobre as Diretrizes e Bases da Educação, que descentralizava as decisões curriculares sob responsabilidade do MEC e instituía a obrigatoriedade do ensino de Ciências nas séries ginasiais. Muito embora, nesse período, importantes avanços tenham sido alcançados, o modelo de ensino que prevalecia no Brasil era o de uma escola tecnicista, voltada para atender o processo de desenvolvimento tecnológico das indústrias (WALDHELM, 2007)

Segundo Waldhelm (2007), de maneira assertiva, os avanços tecnológicos na educação levam a refletir que a escola deve ser pensada sempre pelo viés de um ambiente em constantes transformações, até porque se vive em uma sociedade de mudanças, e, portanto, percebemos que, ao longo da história da educação brasileira, o ensino de Ciências sofreu várias modificações e adaptações para atender ao contexto político e social do período, o que demandou reformulações na legislação. Com isso, tivemos uma ampliação das Ciências no currículo escolar e o aumento da sua carga horária, além de reforçar a ideia de que desenvolvia o espírito crítico (WALDHELM, 2007).

Muitas foram as mudanças no ensino ocorridas no país, sob diretas influências externas. Por conta disso, no ano de 1971, por intermédio da Lei ${ }^{\circ} 5.692$, o ensino de Ciências passou a ter caráter obrigatório nas séries finais do antigo primeiro grau, atual segundo segmento do Ensino Fundamental. Essa obrigatoriedade demandava por uma reflexão sobre os procedimentos adotados no processo de ensino de Ciências que era 
pensado num contexto em que prevalecia a repetição de fórmulas, memorização e resolução de extensas listas de exercícios, com ênfase na ideia de que o conhecimento científico produzido cabe a uma minoria e não pode ser questionado (MOREIRA, 2019).

A partir de 1997, com a aprovação dos Parâmetros Curriculares Nacionais (PCNs), dentre eles o PCN de Ciências, traçava-se o objetivo do ensino de Ciências, desenvolver nos alunos a capacidade de identificar os problemas que emergem da natureza, ou que com ela tem relação, por meio de observações, de suposições e da capacidade de dar soluções aos problemas de forma emancipada (BRASIL, 1998).

A aprovação da LDB, em 1996, e dos PCNs, em 1997, exigia investimento em diversas frentes para a melhoria da educação no Brasil, dentre essas frentes, destacamos a formação inicial e continuada para os professores. Mas, esse investimento não ocorreu de forma que pudesse atender à ampla demanda, pois, ainda hoje, o ensino de Ciências exibe baixos resultados no PISA, por exemplo, mesmo que tenhamos iniciativas governamentais que buscam pela melhoria desse ensino (WALDHELM, 2007).

Esse mau desempenho pode estar diretamente ligado à formação de professores, que perpassa por um modelo de formação fragmentada, que prima por um ensino desconexo da realidade dos alunos, e não se articula com as vivências dos futuros docentes. Entretanto, foi com a aprovação e implementação da atual LDB, que subsidiou a construção dos PCNs, que as propostas dos cursos de formação de professores, em especial na área de Ciências, começaram a considerar as reflexões a respeito das práticas pedagógicas desenvolvidas em sala de aula. Foi a partir disso que demandou por uma formação em educação em ciências que, segundo Moreira (2019, p. 1),

\footnotetext{
(...) tem por objetivo fazer com que o aluno venha a compartilhar significados no contexto das ciências, ou seja, interpretar o mundo desde o ponto de vista das ciências, manejar alguns conceitos, leis e teorias científicas, abordar problemas raciocinando cientificamente, identificar aspectos históricos, epistemológicos, sociais e culturais das ciências.
}

Tal perspectiva, no panorama contemporâneo, demanda dos professores um entendimento mais aprofundado sobre as inovações científicas e tecnológicas, e proporciona um diálogo mais crítico e reflexivo em sala de aula entre professor e aluno, demandando por metodologias que façam a conexão entre educação e o contexto social, 
político e econômico. Desse modo, inferimos que o ensino de Ciências é tão importante para a formação intelectual e social dos sujeitos como quaisquer outros conhecimentos, e, por essa razão, seja tão essencial os professores desenvolverem atividades que permitam aproximar a teoria da prática.

Nesse cenário, Carvalho et al. (2007) asseguram que o resultado positivo do trabalho do professor de Ciências se relaciona com a habilidade de articular os métodos educacionais às práticas sociais, ou seja, o trabalho docente em sala de aula deve aprimorar nos alunos a competência de relacionar os conhecimentos científicos produzidos pela humanidade com a vida em sociedade, possibilitando um conhecimento mais significativo para os sujeitos, bem como promovendo o pensar crítico a respeito do mundo que os cercam.

\section{FORMAÇÃO DO PROFESSOR DE CIÊNCIAS}

Nos últimos anos a formação docente tem ocupado destaque no cenário brasileiro. Para Tardif $(2002 ; 2004)$ e Nóvoa $(1995 ; 2009)$, essa preocupação adquiriu maior destaque, em especial, a partir da década de 1990, quando se buscou destacar a necessidade de se ter um olhar mais atento para a formação inicial dos professores e para os aspectos ético-epistemológicos que os programas curriculares dos referentes cursos de formação docentes têm apresentado. Quanto à formação dos professores de Ciências, os trabalhos de Nascimento, Fernandes e Mendonça (2010) merecem atenção, por fazerem um traçado histórico de como a perspectivas de ensino de ciências no Brasil, influenciado por acontecimentos políticos e econômicos, demarcaram diretamente na formação dos professores dessa disciplina.

Segundo os autores, o processo de formação desses profissionais perpassou os pressupostos educativos que se alinhavam com a psicologia comportamental, a concepção de que o ensino de ciências deve ser meramente tecnicista, onde o professor passou a ser preparado para "[...] para memorizar as informações científicas que seriam exigidas dos estudantes e aplicar procedimentos didáticos sugeridos por especialistas em educação" (NASCIMENTO; FERNANDES; MENDONÇA, 2010, p. 234) 
Tais debates realçam os desafios que os professores enfrentam em seu fazer pedagógico nas escolas, considera uma atividade complexa. O professor, além de constantemente fazer escolhas difíceis, depara-se cotidianamente com um de seus maiores desafios: ter uma prática pedagógica que possibilite o desenvolvimento dos alunos pelo nível de conhecimento de cada um, pois, o docente precisa atuar de maneira que todos tenham as condições para avançar, sem que nenhum seja prejudicado.

Gatti (2000) assegura que não é somente o domínio teórico ou metodológico que agregam à formação do professor, mas a sua capacidade de relacionar a saberes muito mais amplos, contextualizando-os aos modos de vida dos sujeitos. Nessa perspectiva, o fazer pedagógico é muito mais rico do que somente o 'saber fazer', e o professor precisa dar sentido a essas práticas em sala de aula, agregando-as à vida dos alunos. E o professor de Ciências, em especial aqueles que atuam nas escolas do campo, têm inúmeras possibilidades de explorar seus conteúdos a partir do cotidiano dos alunos.

$\mathrm{Na}$ Resolução nº 02/2015 do Conselho Nacional de Educação, referente às Diretrizes Curriculares Nacionais para a Formação de Professores (BRASIL, 2015), há uma série de recomendações em torno da necessidade de se estabelecer, entre a formação docente e a educação básica, uma articulação permanente, nas diferentes etapas e modalidades, incluindo a educação do campo. Essa relação deve ocorrer “[...] nas diferentes áreas do conhecimento e com integração entre elas, podendo abranger um campo específico e/ou interdisciplinar" (BRASIL, 2015), levando em consideração a diversidade étnico-cultural de cada comunidade onde a escola está inserida.

Nessa direção, a formação precisa ser construída de forma que dê suporte ao professor, no sentido de que o mesmo esteja preparado para abordar saberes que transcendem aos currículos, de forma transversal, desde o início da formação, introduzindo construção de projetos pedagógicos diferenciados, que promulguem os vínculos do processo formativo a partir do chão da escola básica, como vem ocorrendo nos cursos de Licenciatura em Educação do Campo.

Tardif (2004) argumenta que a docência se institui por meio de uma longa escolarização, cuja função é oportunizar conhecimentos teóricos e técnicos que se instrumentalizam no trabalho. Esses conhecimentos são aperfeiçoados a partir da vivência 
do trabalho docente, por meio da qual o professor se familiariza com seu ambiente e com a organização escolar, de modo a compreender a dinâmica institucional e se apropriar, paulatinamente, dos saberes necessários ao desenvolvimento de suas ações pedagógicas. Para o autor, a formação perpassa pelos Saberes Disciplinares, os Saberes Curriculares e os Saberes Experienciais, compreendendo-se que o trabalho docente depende dessa relação dialógica entre os diferentes saberes, como estratégias pelas quais o professor vai se construindo.

Assim, para Freire (2011), a profissão docente transcorre por diferentes saberes e, desse modo, aponta três dimensões: 1) os referentes à prática docente, ao exercício da profissão; 2) os referentes ao processo de ensinar, em que ensinar não é transferir conhecimento; e, 3) os referentes à especificidade da espécie, em que ensinar é uma especificidade humana, pois "O educador democrático não pode negar-se o dever de, na sua prática docente, reforçar a capacidade crítica do educando, sua curiosidade, sua insubmissão" (FREIRE, 2011, p. 28).

Nessa perspectiva, o professor necessita ter consciência de que o ser humano é um sujeito inacabado, ou seja, está em um processo contínuo de formação. Daí a importância dessa percepção do outro como alguém que experimenta e explora o conhecimento de diferentes formas. No entanto, para que isso aconteça, é necessário que o professor dê autonomia aos alunos para que nas vivências do contexto escolar haja momentos de aprendizagens significativas. Por essa razão é que ensinar é uma atitude humana e deve ser levada a sério pelo educador, pois, o comprometimento com sua formação é algo substancial ao seu fazer pedagógico, uma vez que “(...) o professor que não leva a sério sua formação, que não estuda, que não se esforça para estar à altura de sua tarefa, não tem força moral para coordenar as atividades de sua classe" (FREIRE, 2011, p. 89-90).

\section{O PROFESSOR DE CIÊNCIAS DAS ESCOLAS DO CAMPO DE PORTO DE MOZ (PA)}

Expomos, a seguir, alguns aspectos representativos dos professores que atuam nas escolas do campo, com a disciplina de Ciências, em Porto de Moz (PA). Inicialmente, constatamos, junto à Secretaria Municipal de Educação (SEMED), que todos os 11 (onze) 
professores que atuam na disciplina de Ciências, nas escolas do campo, não possuem formação na área.

Dos professores que foram nossos interlocutores, destacamos a identificação dos mesmos e sua relação com as escolas nas quais trabalham, tempo de atuação e formação, conforme está descrito no quadro 1.

Quadro 1: Perfil dos interlocutores

\begin{tabular}{|c|c|c|c|}
\hline Perfil & Professor A & Professor B & Professora C \\
\hline Idade & 34 & 32 & 27 \\
\hline $\begin{array}{c}\text { Disciplina que } \\
\text { atua }\end{array}$ & $\begin{array}{c}\text { Ensino Religioso, } \\
\text { Educação Física, } \\
\text { CFB e Espanhol. }\end{array}$ & $\begin{array}{c}\text { Ensino Religioso, } \\
\text { Matemática, Ensino } \\
\text { das Artes, História e } \\
\text { CFB. }\end{array}$ & $\begin{array}{c}\text { Língua Portuguesa, } \\
\text { Matemática e CFB. }\end{array}$ \\
\hline $\begin{array}{c}\text { Escola em que } \\
\text { atua }\end{array}$ & Ribeirinha $^{6}$ & Estrada $^{7}$ & Ribeirinha \\
\hline Formação & $\begin{array}{c}\text { Especialista em } \\
\text { Psicopedagogia }\end{array}$ & Magistério & $\begin{array}{c}\text { Ensino Médio/ } \\
\text { Cursando Educação } \\
\text { do Campo (Ciências } \\
\text { da Natureza) }\end{array}$ \\
\hline
\end{tabular}

O professor "A" atua em uma escola ribeirinha, iniciou em 2006 como professor contratado e passou a ser do quadro efetivo em 2014, mas com a disciplina de Ciências está trabalhando há um ano e dois meses. O professor "B”, por sua vez, atua como docente desde 2009, por meio de contrato e está trabalhando em uma escola da estrada, e trabalha na disciplina de Ciências há cinco anos. Já a professora “C”" trabalha desde 2014 em uma escola ribeirinha, como contratada, mas, apesar de atuar há cinco anos na educação, em 2019 está sendo o primeiro ano que atua com a disciplina de Ciências.

Pelas informações iniciais, percebe-se que os professores possuem diferentes formações, inclusive dois deles não têm graduação, e o que possui não é na área de Ciências, mas em Pedagogia, que o habilita para atuar apenas nos anos inicias do ensino fundamental. Os professores atuam em diferentes disciplinas, além de Ciências.

\footnotetext{
${ }^{6}$ Localizadas às margens dos rios e/ou igarapés

${ }^{7}$ É uma espécie de rodovia municipal que liga determinadas comunidades rurais à sede do município.
} 
A partir desses dados, constatou-se que nenhum dos professores que atuam com a disciplina de Ciências tem formação adequada para exercer a mesma, contrariando o que preconiza a LDB, em seu artigo 62, quando assegura que "A formação de docentes para atuar na educação básica far-se-á em nível superior, em curso de licenciatura plena [...]" (BRASIL, 1996). Nesse sentido, buscamos identificar os motivos pelos quais esses professores atuam com essa disciplina.

Segundo o professor "A", ele trabalha com a disciplina de Ciências a convite da SEMED, porque na escola em que atua não tem professor da área. Naquela ocasião, o único questionamento feito por parte da SEMED ao professor foi se ele tinha domínio de conteúdo da disciplina:

"Então falei que sim; assim, me entregaram a turma para ministrar a disciplina. [...]Eu aceitei porque a gente trabalha com a disciplina, muitas vezes, não por afinidade, mas por necessidade financeira, assim como para completar a carga horária que recebemos do município” (Professor A).

No relato do professor "B", ele afirma que atua na disciplina de Ciências por falta de profissional qualificado:

“(...) na verdade é mais uma carência do município por não 'terem' professores suficientes na área [de Ciências] para atuar no espaço rural" (Professor B, Grifos nosso).

A partir da fala dos professores, observa-se que não há, por parte da SEMED, nenhuma preocupação com os pré-requisitos necessários para a lotação do profissional em determinadas disciplinas, como Ciências, por exemplo, o que torna frequente a atuação sem formação adequada para proceder em disciplinas específicas nas escolas do campo.

Por não possuírem formação na área de Ciências da Natureza, procurou-se investigar quais são as suas percepções sobre a disciplina de Ciências:

(..) A ciências traz para nós não somente conhecimentos da natureza, mas também conhecimento da vida. (Professor A, Grifos nosso).

(...) Os conteúdos de ciência em sua maioria são voltados para as questões ambientais, humanas e áreas afins. Isso sem falar que todos os dias, mesmo sem perceber estamos fazendo ciência em nosso dia a dia. (Professor B, Grifos nosso). 
(...) assim como todas as disciplinas, ciências ajuda os alunos a entenderem o mundo em que estão inseridos, possibilita melhorar suas práticas cotidianas. Melhora de modo geral, nosso modo de ver a vida (Professora $\mathrm{C}$, Grifos nosso).

De acordo com os professores, o ensino de Ciências nas escolas do campo amplia a visão do mundo no qual o aluno está inserido, levando-o a compreender os problemas de contexto social. Suas falas estão parcialmente alinhadas com o que preconiza os PCNs, quando assegura que o ensino de Ciências no segundo segmento do Ensino Fundamental deve desenvolver "(...) competências que lhe permitam compreender o mundo e atuar como indivíduo e como cidadão, utilizando conhecimentos de natureza científica e tecnológica (BRASIL, 1998, p. 32).

Por não possuírem formação inicial na área de Ciências, indagou-se aos professores se eles encontravam dificuldades para ensinar Ciências e quais seriam elas:

A maior dificuldade é com relação ao $9^{\circ}$ ano, nele já tem bastante cálculo e o que se observa é que o aluno já vem com uma dificuldade muito grande da matemática e chega no $9^{\circ}$ ano, que também envolve cálculo nas disciplinas de CFB. aí fica difícil trabalhar. [...]. Eles [os alunos] não tinham noções básicas do que eles já deveriam saber sobre a disciplina. É muito difícil trabalhar com aluno que não teve uma base bem trabalhada em relação à matemática. Assim como os alunos sentem dificuldades em entender os conteúdos, eu sinto dificuldade em repassar os conteúdos também. Porque quando o professor vai para a sala do $9^{\circ}$ ano, ele não tem a intenção de alfabetizar, explicar o que é multiplicação, divisão, essas coisas. A dificuldade maior é essa aí. Até porque nossa formação não traz muitos cálculos, porque na Pedagogia vimos superficialmente cálculos, ou muitas vezes nem se vê. (...) meu problema mesmo é o cálculo [risos]. (Professor A, grifos nosso).

Uma das dificuldades é a falta de formação na área de Ciências, isso remete a dificuldade com o conteúdo de $9^{\circ}$ ano que já entra Física e Química, ou seja, cálculo. Sinto essa dificuldade desde quando iniciei a disciplina de CFB. $\underline{A}$ maioria não domina as quatro operações fundamentais da matemática (Professor B, Grifos nosso).

Devido eu estar concluindo o curso de Educação do Campo - Ciências da Natureza, trabalhar com a disciplina de CFB se tornou menos complicado, pois a formação nessa área me possibilita trabalhar com mais segurança com os conteúdos, diferente dos professores que não têm formação na área. Eu percebo a grande dificuldade deles em trabalhar com essa disciplina, $\underline{e}$ os alunos apresentam dificuldades com a Matemática (Professor C, Grifos nosso).

Conforme os enunciados dos professores, foi possível compreender que as dificuldades enfrentadas por eles são inúmeras, especificamente quando se trata de conteúdos que envolvem a Matemática, presentes nas disciplinas da área de Ciências da 
Natureza. Os PCN's recomendam a relevância da Matemática não apenas nessa área, como também em outras: “[...] também é um instrumental importante para diferentes áreas do conhecimento, por ser utilizada em estudos tanto ligados às ciências da natureza quanto em outros estudos [...]" (BRASIL, 1998, p. 24).

A narrativa do Professor "B" corrobora com a da Professora "C", que destaca justamente essa necessidade de profissionais formados na área de Ciências, o que poderia dirimir tais problemas. Concebe-se que é necessário ampliar a discussão sobre a necessidade de atuação de professores com formação adequada para agir nas diferentes áreas. Nesse segmento, Tardif (2002, p. 39) assegura que “(...) o professor ideal é alguém que deve conhecer sua matéria, sua disciplina e seu programa, além de possuir certos conhecimentos relativos às Ciências da Educação e à Pedagogia e desenvolver um saber prático baseado em sua experiência cotidiana com os alunos"

Constatou-se que a professora "C" relata que não tem a mesma dificuldade com os conteúdos de Ciências, isso pode ser justificado pelo fato da profissional estar concluindo sua graduação na área de Ciências, ou seja, a formação inicial do professor é fundamental para desenvolver um trabalho de qualidade, como ressalta Tardif (2004) sobre a importância dos conhecimentos científicos para os profissionais da educação.

Porém, a professora “C”" traz à tona os obstáculos encontrados para se trabalhar a disciplina nas turmas multisseriadas. Segundo ela, os diferentes níveis de aprendizagem refletem na dificuldade de compreensão de conteúdo.

\footnotetext{
Os alunos das escolas do campo têm uma dificuldade muito grande na disciplina, isso também é fruto de uma educação que aqui no município ainda é ofertada: a famosa turma multissérie, onde o professor precisa trabalhar com mais de uma turma em uma única sala e, na melhor das hipóteses, é pegar um público do mesmo nível de ensino, pior é trabalhar com turmas desde o fundamental menor tudo junto. Isso é preocupante e tem influenciado de forma negativa na aprendizagem dos alunos, não somente em CFB, mas em todas as áreas do conhecimento (Professora $\mathrm{C}$, grifos nosso).
}

Segundo Hage (2011), nas comunidades rurais da Amazônia, as turmas multisseriadas são uma realidade há muitos anos, e isso não é diferente no município investigado. Segundo o censo escolar de 2018 (INEP, 2019), em Porto de Moz existem 159 (cento e cinquenta e nove) turmas multisseriadas nos anos finais do Ensino Fundamental. Há turmas que são agrupadas por ano: $6^{\circ}$ e $7^{\circ}, 8^{\circ}$ e $9^{\circ}$, ou todos os anos $\left(6^{\circ}\right.$ 
ao $9^{\circ}$ ) em uma única sala. Essas turmas são organizadas sob a justificativa dos gestores municipais de que há um número mínimo de alunos para se abrir turma individual. Porém, não há nenhuma referência a isso na legislação vigente, mas as Secretarias Municipais de Educação, como a de Porto de Moz, baixam portarias determinando esse número.

Além desses problemas salientados, segundo os entrevistados, a falta de material didático para a realização das aulas, dificultando o processo de ensino e aprendizagem.

(...) a precarização das escolas do campo, pois temos muitas dificuldades em trabalhar metodologias que necessitem de recursos que não disponibilizam no campo, como por exemplo, o uso de datashow, o mapa mundi, o globo terrestre, mas, enfim, levamos como podemos. (Professora C, Grifos nosso).

A partir dos apontamentos dos entrevistados, buscou-se aprofundar a discussão com intuito de compreender como a oferta desses recursos podem contribuir no processo do ensino de Ciências:

\begin{abstract}
O único recurso didático que a escola oferece são os livros mesmo. Isso muito escasso, alguns eu tenho que vir até a SEMED procurar no depósito. Alguns livros lá já estão ultrapassados, por estarem lá há muito tempo e não serem entregues aos professores no início do ano. Mas é a realidade nossa (...) (Professor A, grifos nosso).

O livro didático, computador, duas multifuncionais, acesso à internet, que faz com que o aluno tenha uma visão mais ampla do conteúdo. Uma mini livraria, com livros do $1^{o}$ ao $9^{\circ}$ ano e agora com novas exigências da $B N C C^{8}$. (Professor $\mathrm{B}$, grifos nosso).

Os livros didáticos, televisão e 'data show'. (Professora C)
\end{abstract}

Nos relatos, é possível notar o descontentamento do professor "A", ao descrever que sua escola dispõe somente de livros didáticos, e que, em sua maioria, está desatualizado. É perceptível o descaso do poder público com a educação do campo, que, segundo o professor, não desenvolve um planejamento adequado para a distribuição dos livros didáticos entre as escolas, o que contribui para que diversos desses livros se estraguem.

Por outro lado, a realidade do professor "B" se diferencia em muitos aspectos dos demais. A escola onde ele trabalha tem materiais didáticos, como computador e máquinas

\footnotetext{
8 A Base Nacional Comum Curricular, é um documento de caráter normativo que define o conjunto orgânico e progressivo da aprendizagem das crianças e foi aprovado para a educação infantil e ensino fundamental no estado do Pará em dezembro de 2018 pelo CEE/PA (PARÁ, 2018).
} 
de cópia multifuncional, além de acesso à internet, o que contribui para que os alunos tenham acesso a outros conhecimentos, se forem utilizados de forma adequada, conforme ressalta Borba (2013, p. 3): “[...] a utilização dos recursos tecnológicos mediando o processo ensino e aprendizagem pode se tornar uma vantagem quando estes são bem escolhidos para que possam motivar o aprendizado do educando". Cabe determinar que essas ferramentas, incluindo a internet, tem elevado potencial para a qualificação docente, considerando que esta precisa mediar processos de aprendizagem que demandam um viés indissociável das tecnologias, que fazem parte do contexto dos alunos, inclusive de muitos que são do campo.

Nóvoa (2009) julga que a formação docente precisa incidir para o interior da profissão, ou melhor, ela deve se constituir na prática docente e na reflexão sobre a atividade escolar, e, assim, possibilitar um trabalho relevante para a sociedade, por meio de ações que estejam condizentes com o contexto dos alunos.

Para a professora "C", ter nas escolas outros recursos didáticos, além dos livros, não significa que o uso destes seja garantido, como acontece geralmente com ela. Por mais que a escola disponha de Projetor Multimídia (Datashow) e televisão, não há energia elétrica no período diurno ${ }^{9}$, o que torna inviável utilizar tais recursos pedagógicos.

Essas escolas trazem consigo a realidade de muitas existentes no interior da Amazônia paraense, que têm o livro didático como único recurso pedagógico, e, as que possuem outros recursos não fazem uso dos mesmos por conta da falta de uma estrutura adequada, como a energia elétrica, por exemplo.

Considerando as dificuldades encontradas pelos docentes, os mesmos foram responderam sobre quais metodologias utilizavam nas aulas de Ciências para superar tais desafios:

Olha, eu procuro ser mais dinâmico possível, eu faço algumas brincadeiras envolvendo os conteúdos que eu estou trabalhando, eu levo vídeos com aulas explicativas, eu repasso para o celular deles, assim eles estudam também em casa, sem falar do auxílio do livro. (Professor A, Grifos nosso).

\footnotetext{
${ }^{9}$ A energia elétrica existe na comunidade apenas em parte do horário noturno (de $18 \mathrm{hs}$ às $23 \mathrm{hs}$ ), gerada por meio de um motor que funciona a óleo diesel, que é comprado por meio de "coleta" financeira entre os moradores da comunidade.
} 
Geralmente utilizo a pesquisa de campo em seu próprio espaço. Também há pesquisa feita pela internet. (Professor B, Grifos nosso).

Bem ... trabalho com os livros didáticos fornecidos pela SEMED, faço dinâmica em sala de aula a partir do conteúdo, desenvolvo aulas práticas associando teoria e o cotidiano dos alunos. (Professor C, Grifos nosso).

As afirmativas dos professores sinalizam que eles têm tomado iniciativas que enveredam para aulas que fujam do modelo de educação bancária contestado por Freire (2011). Requer destaque, ainda, a inserção das Tecnologias da Informação e Comunicação (TIC), com uso de vídeos, internet e celular, o que mostra que o Professor "A" tem buscado usar recursos alternativos que podem contribuir para superar determinadas dificuldades por eles encontradas.

Por não se ter percebido, nessas falas, a pretensão pela relação dos conteúdos escolares com os modos de vida dos alunos e de suas comunidades de pertença, procurouse conhecer de que forma isso acontecia:

Olha, é muito comum a gente fazer isso na parte que fala sobre as plantas ou plantio. A gente utiliza muito a realidade deles lá, eles vivem do campo. Eles plantam, colhem, caçam, eles pescam, então tudo isso está envolvido dentro da disciplina de CFB. É nessa hora que pegamos os conteúdos e levamos para a realidade dos alunos, lá ele aprende sobre as estações do ano, porque o sol nasce de um lado e se põe de outro. As pessoas que moram no campo já têm uma base de quando vai chover, até mesmo quando pensamos que não vai chover, eles têm noções de tempo, clima, tudo isso a partir dos conhecimentos que eles adquirem ao longo dos anos. É um conhecimento que é compartilhado conosco. Assim como ensinamos, também aprendemos com os alunos, há um conhecimento mútuo (Professor A, Grifos nosso).

Olha, a maior parte dos conteúdos a gente sempre faz, porque, no geral, sempre os conteúdos de CFB aproximam a realidade do aluno. Geralmente, essa relação com o meio de vida que é feito, a gente sempre espera que seja aplicado em cada lote dos educandos. Outro ponto é com relação ao ambiente e a água, são assuntos que eu sinto interesse deles em participar, talvez seja porque a escola situa-se em local onde existem áreas que já foram derrubadas em grande escala. Quando se toca nos assuntos referentes ao ambiente, eles contribuem bastantes. (Professor B, Grifos nosso).

Sempre que trabalho com conteúdos que são possíveis, faço isso, um exemplo é sobre as plantas, o meio ambiente, a água, solo, etc. (Professora C, Grifos nosso).

Nesse âmbito, os professores acreditam ser relevante a relação entre os conteúdos de Ciências e a vivência dos alunos, os seus modos de vida, de forma articulada. Tais práticas se aproximam daquilo que assegura a LDB, por meio do seu Artigo 28: 
[...] os sistemas de ensino promoverão adaptações necessárias à sua adequação às peculiaridades da vida rural e de cada região, especialmente:

I - conteúdos curriculares e metodologias apropriadas às reais necessidades e interesses dos alunos da zona rural (BRASIL, 1996).

Além disso, o inciso I do Artigo $2^{\circ}$ do Decreto Federal no 7.352/2010 traz como um dos princípios da educação do campo o "respeito à diversidade do campo em seus aspectos sociais, culturais, ambientais, políticos, econômicos, de gênero, geracional e de raça e etnia" (BRASIL, 2010).

Nesse aspecto, Arroyo, Caldart e Molina (2004) já argumentavam que a educação do campo deve estar associada à manutenção de condições para a vida no campo, construindo formas, espaços e relações diferenciadas, com base no ofício coletivo, na articulação entre trabalho e estudo e entre teoria e prática. Os interlocutores revelam que fazem algo, por meio de suas práticas, que contemplem a legislação, todavia, no decorrer da observação em sala de aula, isso não foi perceptível.

Chama a atenção as falas do professor "A", que afirma que os discentes já têm base de muitas coisas que acontecem na natureza, como o clima, o tempo, conhecimentos que foram adquiridos ao longo dos anos. Contudo, esse mesmo educador, em outros momentos da entrevista, declara que os alunos chegam sem nenhum saber na escola: “[...] eles chegaram com a mente vazia em relação a essa disciplina, eles não conseguem entender, ai fica complicado trabalhar dessa forma" (Professor A).

Nas falas do professor "A", depreendemos que o mesmo atrela saber apenas aos conteúdos escolares, não considera que os saberes construídos pelos alunos, doravante suas vivências, têm relevância e podem contribuir no processo de ensino e aprendizagem, se forem bem explorados. A partir dessa afirmativa contraditória, inquiriu-se: o professor consegue, efetivamente, estabelecer relações entre os conteúdos escolares e os modos de vida dos alunos? Como, de fato, ele realiza isso? E como a Ciências pode ajudar na formação desse aluno?

Moreira (2019, p. 1) nos aponta o caminho de qual as ciências deveriam ocupar no processo de ensino e aprendizagem. Segundo o autor é necessária uma ruptura ao modelo de ciência tecnicista, como se fosse um treinamento, para tanto é necessário que os professores passem a construir uma educação em ciências que faça com que o aluno 
vivencie e tenha a possibilidade de "[...] identificar aspectos históricos, epistemológicos, sociais e culturais das ciências"

Para chegar a essa educação em ciências apontada pelo autor, um dos caminhos poderia ser a formação continuada, ofertada pela própria escola ou a SEMED, mas isso não acontece, conforme relatos a seguir.

\begin{abstract}
Não tem! Tanto na área de Ciências, como em qualquer outra área. (...) E, nesse caso, a SEMED deixa muito a desejar, porque eu acredito que a semana pedagógica poderia ser bem mais proveitosa, principalmente para nós trabalhadores do campo, que é uma área completamente diferente da realidade da cidade (Professor $\mathrm{A})$.
\end{abstract}

Não. Geralmente o que ela oferece é o que chamamos de Semana Pedagógica, mas não é específica para CFB (Professor B).

Não tem formação na área (Professora C).

Observamos que as formações ocorrem apenas por intermédio das semanas pedagógicas. Tal formação, deveria ir para além dos conteúdos específicos da área, mas perpassar pela dinâmica das turmas multisseriadas. Hage (2011), salienta que o professor que trabalha em escolas do campo, sobretudo das classes multisseriadas, exerce inúmeras funções, que vão desde a de zelador até o serviço de merendeira; logo, o trabalho docente não está limitado somente à docência, mas a outras atividades paralelas: “[...] ficando responsável pela confecção e distribuição da merenda, realização da matrícula e demais ações de secretaria e da gestão, limpeza da escola e outras atividades na comunidade" (HAGE, 2011, p. 100)

O ensino nas escolas do campo precisa de profissionais qualificados, e, por esse motivo, não se pode perder de vista a grande necessidade de um trabalho formativo voltado para atender as especificidades desse público. Os educadores precisam de incentivos para continuarem na profissão, e, dentre eles, tem-se a valorização, tanto salarial quanto formativa. Olhando para essa realidade, na qual os docentes das três escolas investigadas estão inseridos, acreditamos no quanto a formação profissional em área específica pode fazer a diferença na sua atuação e na vida escolar dos alunos, ou seja, refletirá diretamente no processo de ensino e aprendizagem.

Para tanto, vale pautar que a meta 15, do Plano Nacional de Educação (PNE), não foi cumprida até o momento. Nesta meta, a União, os Estados, o Distrito Federal e os 
Municípios, tinham o prazo de 1 (um) ano, após a aprovação da Lei $n^{\circ}$ 13.005/2014 (BRASIL, 2014) para implantação de uma "política nacional de formação dos profissionais da educação de que tratam os incisos I, II e III do caput do art. 61 da Lei n 9.394”, que buscasse assegurar “(...) que todos os professores e as professoras da educação básica possuam formação específica de nível superior, obtida em curso de licenciatura na área de conhecimento em que atuam" (BRASIL, 2014).

Mas, não se visualizam iniciativas por parte do governo municipal para atender essa meta. Portanto, acredita-se que se esses desafios não forem pensados com muita cautela e responsabilidade, infelizmente, continuar-se-á com um modelo de educação precário, perpetuado nas escolas do campo.

\section{CONSIDERAÇÕES FINAIS}

Foi evidenciado que todos os docentes que atuam na disciplina de Ciências nas escolas do campo do município de Porto de Moz não possuem formação na área. Constatamos, igualmente, que um dos motivos que levam os docentes a ministrarem a disciplina de Ciências sem a formação específica na área, é a necessidade de complementar sua carga horária e melhorar o seu salário mensal, além de suprir a carência de professores habilitados para tal ofício no município.

Identificamos também que justamente por não possuírem formação específica na área, os professores apresentam dificuldades com o domínio de conteúdo, em especial com as nomenclaturas específicas, presentes em alguns assuntos da disciplina, e com os cálculos matemáticos, quando se trata do $9^{\circ}$ ano, nos conteúdos de Física e Química. Dificuldades que ficam mais acentuadas quando esses docentes atuam nas classes multisseriadas.

Nesse aspecto, pautamos que é necessário pensar em um ensino de Ciências compromissado em suprir as mazelas que têm afligido as comunidades camponesas por muitos anos, das quais, o direito a uma educação de qualidade lhe tem sido subtraído historicamente, pois, os povos do campo merecem uma educação que rompa com os paradigmas vigentes, conforme exemplos apontados na pesquisa e, ainda, que esta seja 
ofertada não como aquilo que sobra do meio urbano, mas com a especificidade que lhe é inerente.

Sendo assim, reafirmamos que a educação do campo precisa ser pensada no campo e para os sujeitos do campo, levando em consideração suas experiências sociais, econômicas, culturais e políticas, já que é esse tipo de educação que valoriza a diversidade que necessita ser trabalhada na sociedade. E o ensino de Ciências é capaz de melhorar as condições sociais desses sujeitos em todos os âmbitos, garantindo-lhes, desse modo, o respeito e a dignidade dos povos do campo.

\section{REFERENCIAS}

ARROYO, Miguel Gonzalez; CALDART, Roseli Salete; MOLINA, Mônica Castagna. Por uma educação do campo. Petrópolis: Vozes, 2004.

BORBA, Sara Ingrid. As tecnologias nas escolas do campo: uma questão de direito a cidadania. João Pessoa/PB. UFPB, 2013.

BRASIL, Lei 9394/96 de 20 de dezembro de 1996. Institui as Diretrizes e Bases da Educação Nacional. Diário Oficial da República Federativa do Brasil, Brasília, DF, 23 de dezembro de $1996 . \quad$ Disponível em http://www.planalto.gov.br/ccivil_03/leis/19394.htm. Acesso em 20 abril 2019.

BRASIL, Programa Nacional de Educação do Campo PRONACAMPO: Documento Orientador, Brasília, 2013. Disponível em: http://portal.mec.gov.br/index.php?option=com_docman\&view $=$ download\&alias $=1321$ 4-documento-orientador-do-pronacampo-pdf\&Itemid=30192. Acesso em: 30/05/2019

BRASIL. MEC. PARFOR. Plano Nacional de Formação de Professores da Educação Básica Brasília, DF: MEC, 2009.

BRASIL. Secretaria de Educação Fundamental. Parâmetros curriculares nacionais: ciências naturais /Secretaria de Educação Fundamental. - Brasília: MEC/SEF, 1998. $136 \mathrm{p}$.

BRASIL, Diretrizes curriculares para a formação de professores da educação básica. Brasília: MEC/SEF, 2015 Disponível em: http://portal.mec.gov.br/index.php?option=com_docman\&view=download\&alias $=1771$ 9-res-cne-cp-002-03072015\&category_slug=julho-2015-pdf\&Itemid=30192. Acesso em: 25/08/19.

BRASIL, Lei n 13.005/2014 - Aprova o Plano Nacional de Educação - PNE e dá outras providências. Diário Oficial da República Federativa do Brasil, Brasília, DF 25 
de junho de 2014. Disponível em: http://www.planalto.gov.br/ccivil_03/Ato20112014/2014/Lei/L13005.htm. Acesso em: 02/11/19

BRASIL, Ministério da Educação. Planejando a Próxima Década. Conhecendo as 20 Metas do Plano Nacional de Educação. Ministério da Educação/Secretaria de Articulação com os Sistemas de Ensino (MEC/Sase): Brasília, DF., 2014. Disponível em: http://pne.mec.gov.br/images/pdf/pne_conhecendo_20_metas.pdf Acesso em: 02/11/19.

CARVAlHO, Anna Maria Pessoa de et al. Ciências no Ensino Fundamental: o conhecimento físico. São Paulo: Scipione, 2007.

CHIZZOTTI, Antonio. Pesquisa qualitativa em ciências humanas e sociais. Petropólis, RJ: Vozes. 2006.

FREIRE, P. Pedagogia da autonomia: saberes necessários à prática educativa. São Paulo: Paz e Terra, 2011.

GATTI, B. A. Formação de professores e carreira: problemas e movimentos de renovação. 2. ed. Campinas: Autores Associados, 2000.

HAGE, Salomão Antônio Mufarrej. Por uma escola do campo de qualidade social: transgredindo o paradigma (multi)seriado de ensino. Revista Em Aberto, Brasília, v. 24, n. 85 , p. $97-113$, abr. 2011.

HAGE, Salomão Antônio Mufarrej. Transgressão do paradigma da (multi)seriação como referência para a construção da escola pública do campo. Educ. Soc., Campinas, v. 35, no. 129, p. 1165-1182, out.-dez., 2014.

INSTITUTO NACIONAL DE ESTUDOS E PESQUISAS EDUCACIONAIS. Sinopse estatística da educação básica 2008. Brasília: Inep, 2019. Disponível em: http://inep.gov.br/web/guest/sinopses-estatisticas-da-educacao-basica. Acesso em $02 / 11 / 19$

MOREIRA, M. A. Pesquisa básica em educação em ciências: uma visão pessoal. Porto Alegre, RS [s/n], 2019. Disponível em:

https://www.if.ufrgs.br/ moreira/Pesquisa.pdf. Acesso em 27/07/2019.

NASCIMENTO, F. DO; FERNANDES, H. L.; MENDONÇA, V. M. DE. O ensino de ciências no Brasil: história, formação de professores e desafios atuais. Revista HISTEDBR On-line, v. 10, n. 39, p. 225-249, 11

NÓVOA, Antônio. Os professores na virada do Milênio: do excesso dos discursos à pobreza das práticas. Educação e Pesquisa, São Paulo, v. 25, n. 1, p. 11-20, jan./jun. 2009.

NÓVOA, Antônio. Profissão professor. Lisboa: Porto Editora, 1995. 
PARÁ. Resolução no 769, de 20 de dezembro de 2018. Aprova o documento curricular para o documento infantil e ensino fundamental do estado do Pará no sistema estadual de ensino do Pará. Conselho Estadual de Educação. Belém (PA), 2018. Disponível em: http://www.cee.pa.gov.br/sites/default/files/doc14438020181220141136merged.pdf Acesso em 02/11/19

TARDIF, M.; LESSARD, C. O trabalho docente: elementos para uma teoria da docência como profissão de interações humanas. Tradução de João Batista Kreuch. 3. ed. Petrópolis, RJ: Vozes, 2004.

TARDIF, Maurice. Saberes docentes e formação profissional. $4^{\text {a }}$ Ed. Rio de Janeiro: Vozes, 2002.

UNIVERSIDADE FEDERAL DO PARÁ. Projeto Pedagógico do curso de Licenciatura em Educação do Campo. Aprovado por meio da Resolução $n^{\circ} 4.703$, de 19 de agosto de 2015. Altamira (PA), 2015. Disponível em: http://facetnoaltamira.ufpa.br/index.php/ppc-edcampo Acesso em: 10/06/19.

WALDHELM, Mônica de Cassia Vieira. Como aprendeu ciências na educação básica quem hoje produz ciência?: o papel dos professores de ciências na trajetória acadêmica e profissional de pesquisadores da área de ciências naturais. Tese (Doutorado em Educação) Pontifícia Universidade Católica do Rio de Janeiro, Rio de Janeiro, 2007. Disponível em: https://www.maxwell.vrac.puc-rio.br/11290/11290_1.PDF. Acesso em $10 / 11 / 19$ 